\title{
Power Management of a Stand-Alone Hybrid (Wind/Solar/Battery) Energy System: An Experimental Investigation
}

\author{
Saindad Mahesar, \\ Mazhar H. Baloch \\ Mehran University of Engg \& Tech, \\ Sindh Pakistan
}

\author{
Ghulam S. Kaloi \\ QUEST Larkana, \\ Campus Sindh Pakistan
}

\author{
Mahesh Kumar, \\ Aamir M. Soomro, \\ Asif A. Solangi, Yasir A. Memon \\ Mehran University of Engg \& Tech, \\ Sindh Pakistan
}

\begin{abstract}
In this manuscript, a hybrid wind/solar/battery energy system is proposed for a stand-alone applications. Windsolar energy sources are used as power generation source in the proposed hybrid energy system (HES), whereas battery is used as energy storing system in order to manage the power flow among various power generation sources and energy storing system. Power management control strategy is also presented for a suggested hybrid system. Through the real load demand and practical weather data (proposed area is Jamshoro, Sindh Pakistan), the system performance is verified under different situations. It is observed that the hybrid system produces maximum power in summer season as compared to other seasons throughout the year. Moreover, the power generated from wind and solar energy contributes $\mathbf{7 7 . 8 8 \%}$ and $\mathbf{2 2 . 1 2 \%}$, respectively. However, it is clearly observed that the HES is cost effective and can be used in remotely rural areas which are isolated from power grid. In future work, the HES can be integrated with the power grid in order to meet the load demand during shortage of power.
\end{abstract}

Keywords-Hybrid; stand-alone; wind; solar; battery; power management; Pakistan

\section{INTRODUCTION}

The growing energy utilization, expanding environmental contamination, high rate and the prompt decline of fossil fuels have made increasing concern towards renewable energy generation sources, i.e., wind energy, solar energy, geothermal, biomass, and tidal energy [1]-[5, [18]. In Pakistan, the renewable energy sources have a huge potential to produce electric power and these resources can play a vital role in overcoming energy crisis [6], [7]. Among these renewable energy resources, solar and wind energy sources are more attractive power producing technologies [1], [2], [8]. The wind and solar energy are abundantly available, free, inexhaustible, and have no emission of greenhouse gases, therefore they are atmosphere friendly [3], [5], [6], [10]. Due to such features, these renewable energy resources can be utilized on large scale to produce power in order to meet load requirement [6]. A huge amount of population are living at rural areas around the globe, where still no power for their social life, and they have very minimum load demand, and still not connected with the power grid system. In order to supply the power to these

Support of the Higher Education Commission Pakistan \& Mehran University of Engineering and Technology, Pakistan is greatly acknowledged. remotely located areas, alternative energy sources such as wind and solar are economical and efficient substitutes [6].

Globally, wind and solar energy resources have their own deficiencies, such as wind is not accessible at all times and solar is accessible only day time, therefore in order to make sure the continuity of power supply to meet the load requirements, it is essential to make wind and solar energy resources along with storage device as a hybrid energy system [9]. The energy storing devices may be battery, flywheel, super capacitor or fuel cell [1], [4], [10]. Hybrid energy system is the integration of two or more than two power producing technologies together with some energy storage system to supply power to the load. Various unconventional energy sources i.e., wind, solar, diesel, fuel cell, gas turbine can be utilized to make a hybrid system [1]. A hybrid energy system is more efficient and provides continuous power to consumers with more reliability than a single source based system [1], [2]. The hybrid energy system is more appropriate for off-grid services to supply remotely located rural regions [10].

In this paper, a hybrid wind/solar/battery energy system is suggested for a stand-alone applications. Solar-wind system is primarily resources of generation in our proposed system, while battery is used as energy storage system and these sources are coupled with AC bus via appropriate converters. The DC load can be supplied through ac/dc rectification [15].

This paper is ordered as follows: in section 2, hybrid system configuration and description is given. In section 3, modeling and overall power management strategy is given. In section 4 , result and discussions is given. While the last section 5 concludes the manuscript.

\section{HYBRID SYSTEM CONFIGURATION AND DESCRIPTION}

\section{A. Hybrid System Configuration}

The proposed configuration of the hybrid i.e., wind/solar/battery system can be shown in Fig. 1. In this system, renewable wind and solar resources are utilized as major energy sources, whereas battery is used as storage device. When the power generation from wind and solar system is excessive, the excessive power is delivered to the battery. When battery becomes fully charged, then extra power will be sent to dump load. While during the deficiencies of 
power generated from wind and solar energy system due to weather issues, the battery backup will supply the power to meet load demand. Through suitable interfacing circuits, various energy sources are coupled with the bus. The proposed hybrid system can be extended easily when other energy generation resources are accessible.

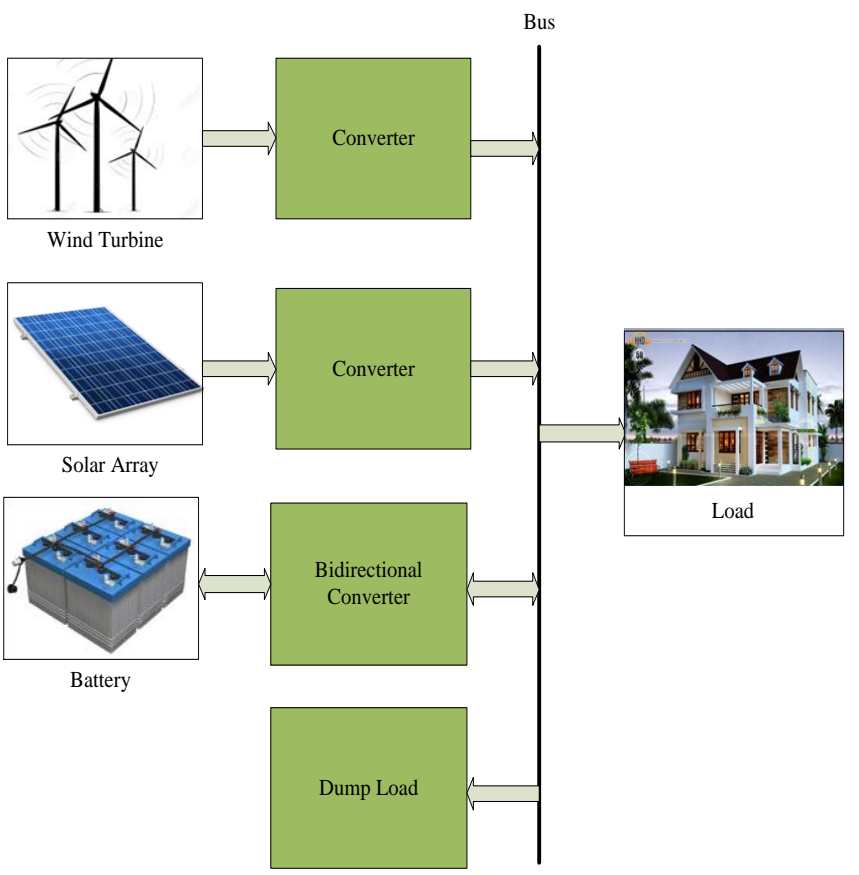

Fig. 1. Schematic diagram of proposed hybrid energy system.

\section{B. System Unit-Sizing}

The process of unit-sizing is considered for a proposed hybrid energy system with the recommended arrangements (as shown in Fig. 1) for domestic electricity supply in Jamshoro. It is clear from the Fig. 2 that minimum load demand is $5.5 \mathrm{~kW}$ while maximum demand is $12.8 \mathrm{~kW}$. The core objective is to correctly size the elements of the hybrid system in order to confirm the reliable power supply to meet the load requirements.

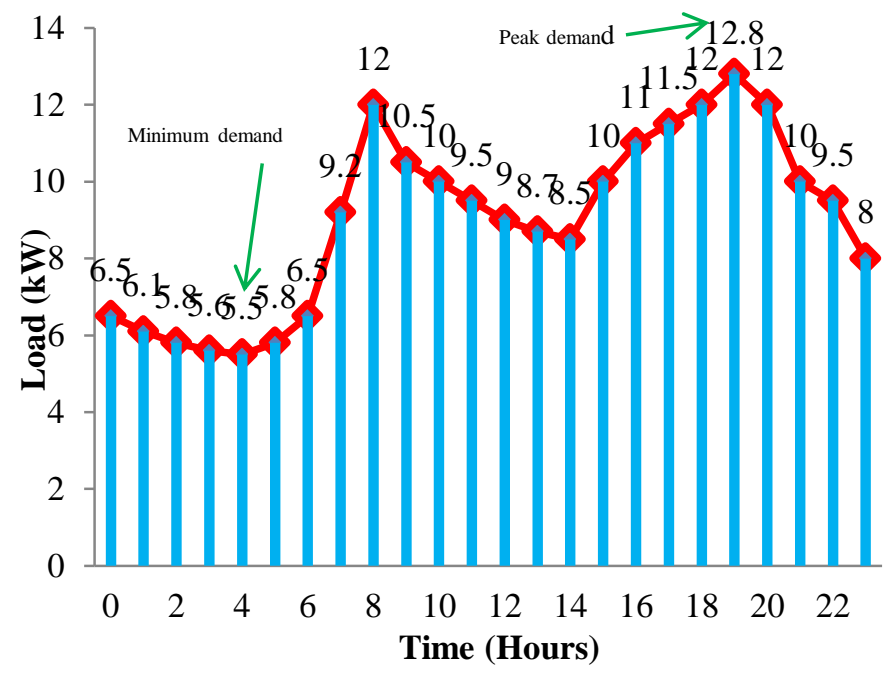

Fig. 2. Hourly average load of five homes in Jamshoro response.
The HES is planned in order to supply five homes in Jamshoro. In this analytical study an hourly average domestic load of five homes in Jamshoro is considered, as shown in Fig. 2. The technique for determining the sizing of solar array is given below:

The capacity factor $\left(K_{c f}\right)$ can be characterized as follows [1, 12]:

$K_{c f}=\frac{P}{P_{\text {rated }}}$

Where $(P)$ and $\left(P_{\text {rated }}\right)$ are the average power output and rated power of a renewable energy resource respectively. The theoretical capacity factor for wind is varies from $0-100 \%$, while in practice it is mostly up to $30 \%$. However, in this study authors have assumed $14 \%$ and $10 \%$ capacity factor for wind solar respectively[1].

The purpose of unit sizing is to reduce the difference between generated power $\left(P_{g e n}\right)$ from alternative energy sources and load demand $\left(P_{\text {dem }}\right)$ for a time period $(\mathrm{T})$, and time considered in this study is only one year data.

$\Delta P=P_{\text {gen }}-P_{\text {dem }}=K_{c f w t g} * P_{\text {wtg rated }}+K_{c f \text { solar }} P_{\text {solar rated }}-P_{\text {dem }}$

Where $P_{\text {wtgrated }}$ and $P_{\text {solar rated }}$ are the power ratings of wind turbine and solar array respectively.

In order to balance the power generation and load demand, the power rating of solar array is given as:

$P_{\text {solar rated }}=\frac{P_{d e m}-K_{c f w t g} * P_{w t g \text { rated }}}{K_{c f \text { solar }}}$

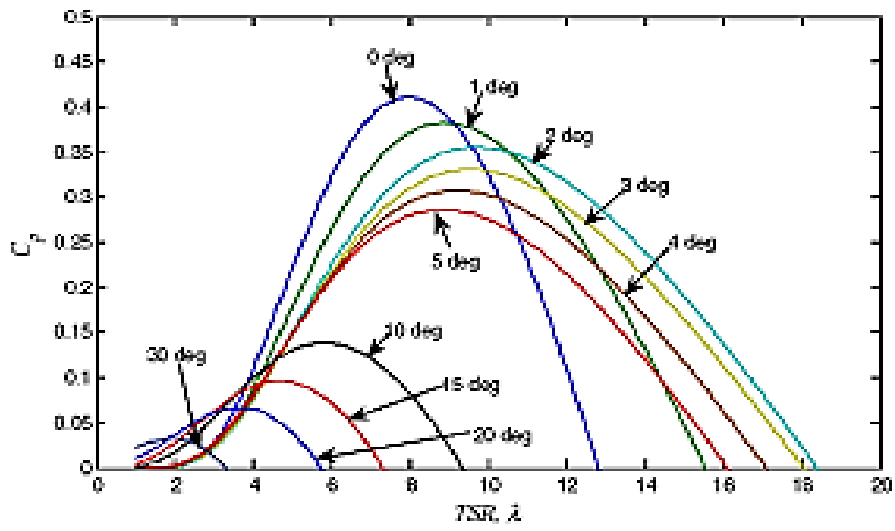

Fig. 3. Characteristics of the WT at different pitch angle response [11], [12], [15].

As shown in Fig. 2, the average load requirement is $9 \mathrm{~kW}$ approx., therefore, according to equation (3), the solar array will be of $20 \mathrm{~kW}$ in size.

The battery is used as storage device and offers backup for the system. The battery should be capable to store surplus power and to supply power to load during deficiency of power generation. The battery bank of $1800 \mathrm{AH}$ rating is utilized in this stand-alone hybrid energy system as shown in Table I. 
TABLE I. SYSTEM COMPONENT PARAMETERS

\begin{tabular}{|l|l|}
\hline Wind Energy System Components & Ratings \\
\hline Rated power of wind turbine & $50 \mathrm{~kW}$ \\
\hline Cut in speed & $3 \mathrm{~m} / \mathrm{s}$ \\
\hline Rated speed & $14 \mathrm{~m} / \mathrm{s}$ \\
\hline Cut out speed & $25 \mathrm{~m} / \mathrm{s}$ \\
\hline \multicolumn{1}{|c|}{ Solar Array } & $20 \mathrm{~kW}$ \\
\hline Power rating & $18 \%$ \\
\hline Efficiency & \multicolumn{2}{|l}{} \\
\hline \multicolumn{1}{|c|}{ Battery } & $1800 \mathrm{AH}$ \\
\hline Capacity & 48 \\
\hline Battery rated voltage &
\end{tabular}

\section{Wind Energy System Model}

The mechanical power taken out from wind turbine $\left(P_{\text {wind }}\right)$ is expressed as follows [1], [2], [11], [13], [15] and [19]:

$$
P_{\text {wind }}=0.5 \rho A v^{3} C_{p}(\lambda, \theta)
$$

Where $\rho$ is the air density in $\mathrm{kg} / \mathrm{m}^{3}$, and its equal to 1.225 $\mathrm{kg} / \mathrm{m}^{3}, A$ is the swept area of blades in $\mathrm{m}^{2}$, its value is taken as $10 \mathrm{~m}^{2}, v$ is the wind speed in $\mathrm{m} / \mathrm{s}$ and $C_{p}$ is the power coefficient and it is the function of the tip speed ratio and pitch angle. The theoretical value of $C_{p}$ is 0.59 (see [20], [21]), while its practical value is varies from 0.2 to 0.4 [11], [12], [15]. In this study $C_{p}=0.3$ is considered.

In this paper, a variable-speed pitch controlled wind turbine is used, in which pitch angle controller have a significant role. The $C_{p}-\lambda$ characteristics of the wind turbine at different pitch angles as shown in Fig. 3. It can be noted from Fig. 3 that the value of $C_{p}$ changes with the change in pitch angle $(\theta)$. Therefore, wind turbine output power can be controlled by means of pitch angle control.

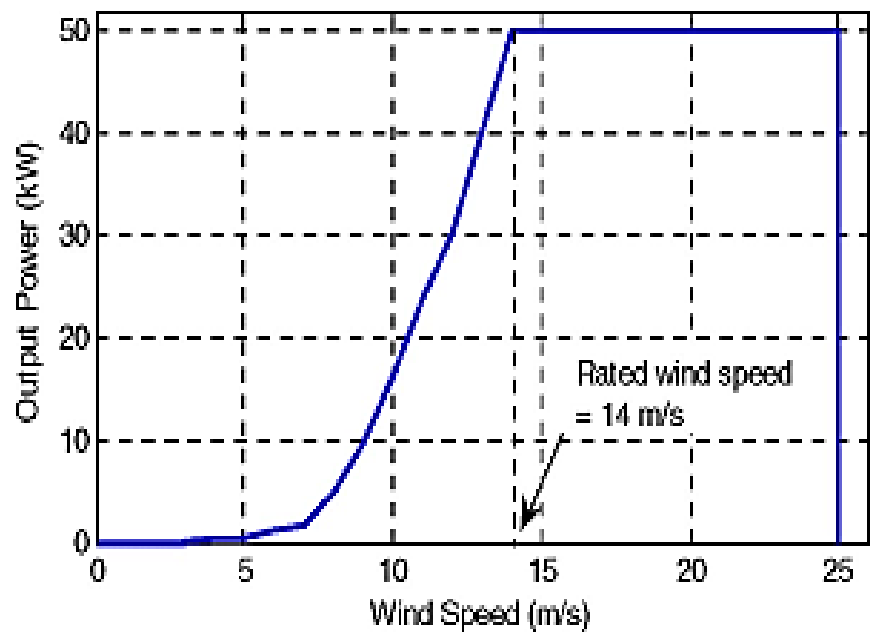

Fig. 4. WT output power vs. Wind speed response [11, 19].
The wind turbine output power versus wind speed characteristics are shown in Fig. 4. It can be observed from Fig. 4 that wind turbine output power retains constant when wind speed is higher than rated speed (i.e., $14 \mathrm{~m} / \mathrm{s}$ ), despite the wind turbine can generate furthermore power. This can be done with pitch angle control in order to avoid rotor over speeding and to safeguard electrical system. In this proposed study, the system will be taken out of operation when the wind speed is greater than cut-out speed (i.e., $25 \mathrm{~m} / \mathrm{s}$ ) in order to protect system.

\section{Solar Energy System Model}

In solar power generation system solar energy is directly transformed into electrical energy. A solar power generation system comprises of one or more than one photovoltaic panels in series or parallel in order to deliver required voltage and current. Solar power generation system is the most favorable source due to eco-friendly. The output power of the solar array depends upon the area of the solar array, solar irradiance and efficiency of the solar array.

The power extracted from solar array can be calculated as follows [15], [16]:

$$
P_{\text {solar }}=A^{*} H * \eta
$$

Where $A$ is the area of the solar array, $H$ is solar irradiance and $\eta$ is the efficiency of solar array. The Fig. 5 shows the I-V characteristic curves at different solar irradiance (at $25{ }^{\circ} \mathrm{C}$ ). It can be observed from Fig. 5 that greater the solar irradiance, higher will be the short circuit current $I_{s c}$ and open circuit $V_{o c}$ voltage. Hence higher will be the solar output power.

Fig. 6 shows the impact of temperature on solar model performance, it can be shown that lesser the temperature, higher will be the solar output power and larger will be the $V_{o c}$ [4], [14].

\section{E. Battery System}

The battery is the necessary component of the hybrid system in order to store surplus energy produced by the hybrid system and to deliver stored energy when the energy generated by the wind and solar energy sources is insufficient to meet the load requirements. Various types of batteries are available i.e., Nickel-Cadmium, Lithium-Iron, Lead-Acid, whereas LeadAcid battery is commonly used to store and supply the energy. For hybrid energy system, the Lead-Acid batteries are less costly and more efficiently [4], [13]-[15].

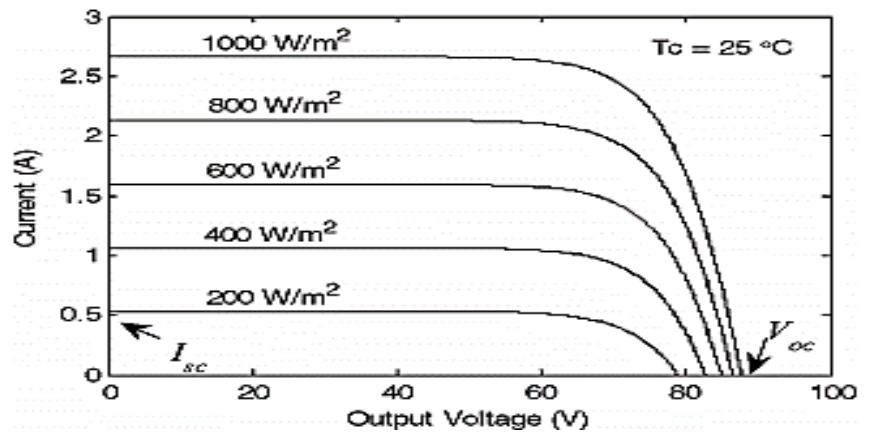

Fig. 5. V curves of solar model at different irradiances response [15], [16]. 


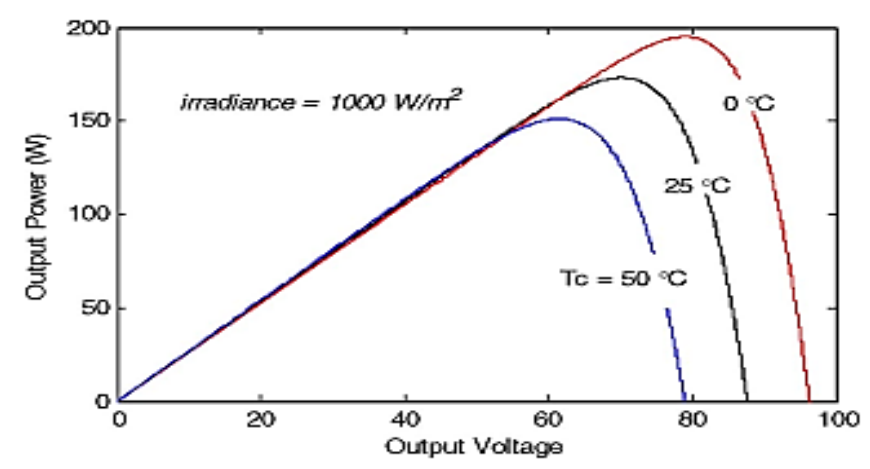

Fig. 6. P-V curves of solar model at different temperature response $[4,14]$.

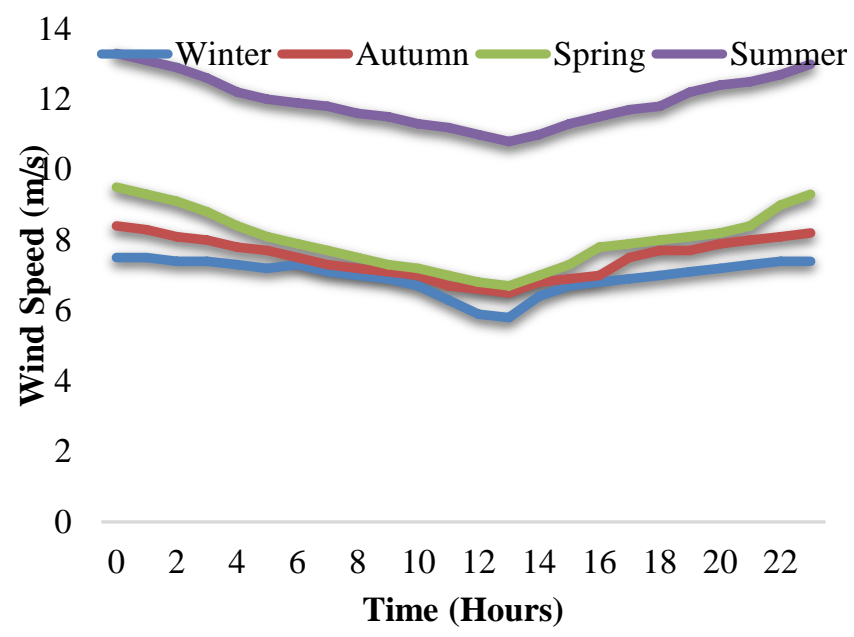

Fig. 7. Wind speed data response (at a height of 50m).

\section{Modeling AND Power Management StRATEGy}

In this proposed hybrid system, wind and solar energy sources are utilized as chief power producing sources. The power produced by these energy sources are weather dependent, therefore battery is used to store extra power and to supply it when required by the load [2]. In multisource hybrid energy system, it is required to have an overall control and power management strategy among various energy sources. The difference between power produced by energy sources and requirement of the load is given as:

$P_{\text {net }}=P_{\text {wind }}+P_{\text {solar }}-P_{\text {load }}$

Where $P_{\text {wind }}, P_{\text {solar }}$ and $P_{\text {load }}$ are wind output power, solar power and load demand in $k W$ respectively.

The main control strategy is that, the surplus power generated by the wind and solar energy sources $\left(P_{n e t}>0\right)$ is delivered to the battery. Therefore, (6) will become:

$P_{\text {wind }}+P_{\text {solar }}=P_{\text {load }}+P_{\text {battery }} \quad ; \quad P_{n e t}>0$

while during shortage of power generation from wind and solar sources $\left(P_{n e t}<0\right)$, the battery supplies power to the load. Therefore, the equation will become:

$P_{\text {wind }}+P_{\text {solar }}+P_{\text {battery }}=P_{\text {load }} \quad ; \quad P_{\text {net }}<0$

\section{RESUlt AND DisCUSSIONS}

Analytical studies has been done in order to verify the performance of the proposed system under diverse conditions by using experimental weather data collected at proposed site. In this analytical study an hourly average domestic load of the five homes in Jamshoro is used. The wind speed and weather data is obtained from Pakistan Metrological Department (PMD) [17]. This study carried out for the management of power during four seasons throughout the year. The load demand data is kept similar for the four seasons of the year. The results for the four seasons of the year are discussed in the following section.

\section{A. Four Seasons (Winter/Spring/Summer/ Autumn) Descriptions}

The wind speed and solar irradiance are lower in winter season (December-February), spring season higher than winter season (March-May), summer season (June-August) is higher than winter, spring and autumn seasons of the year, and autumn season (September-November) is higher than winter season but lesser than spring and summer seasons. From four seasons, the hourly wind speed (at a height of $50 \mathrm{~m}$ ), solar irradiance and temperature data for a period of 24 hours are shown in Fig. 7, 8 and 9, respectively. The generated wind power and solar power over 24 hour's period of the day are shown in Figs 10 and 11 respectively. During excessive power generated from wind and solar sources $\left(P_{n e t}>0\right)$, the extra power available is supplied to the battery to store while during shortage of power generated $\left(P_{n e t}<0\right)$, than battery will supplies the power to the load, as shown in Fig. 12. In Fig. 12, positive value shows the excessive power available, which can be supplied to the battery while negative value shows the power supplied by the battery bank to meet load requirement.

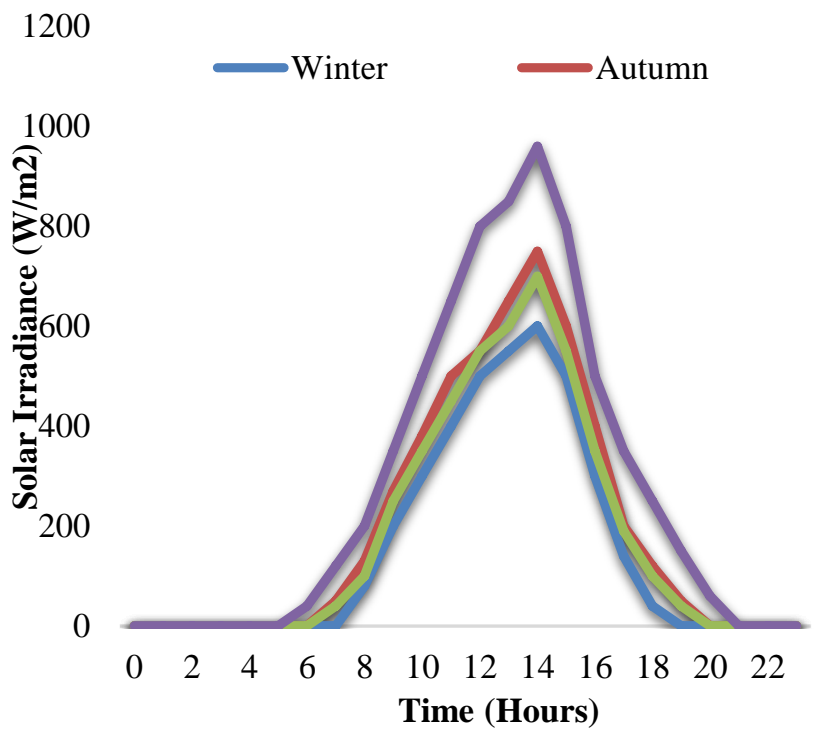

Fig. 8. Solar irradiance data response. 


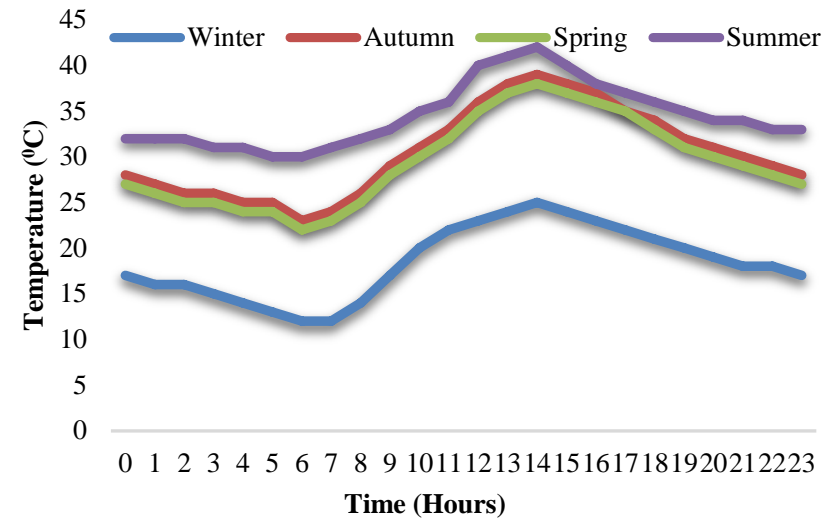

Fig. 9. Temperature data response.

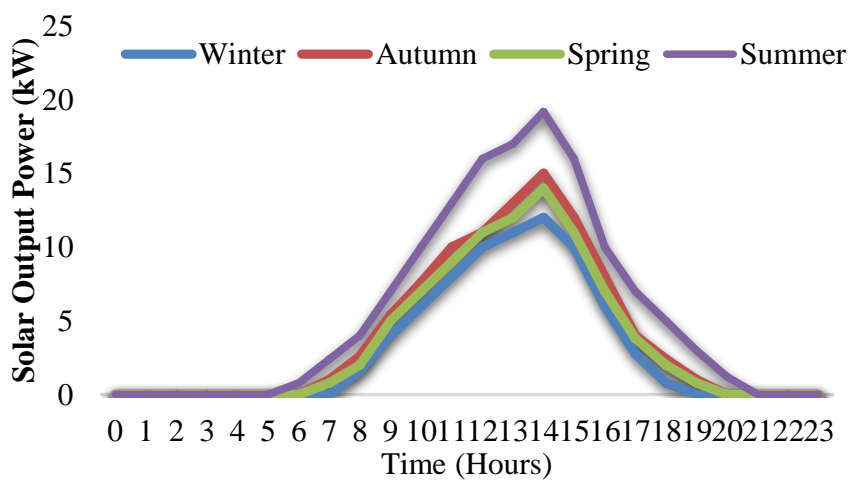

Fig. 10. Wind power response.

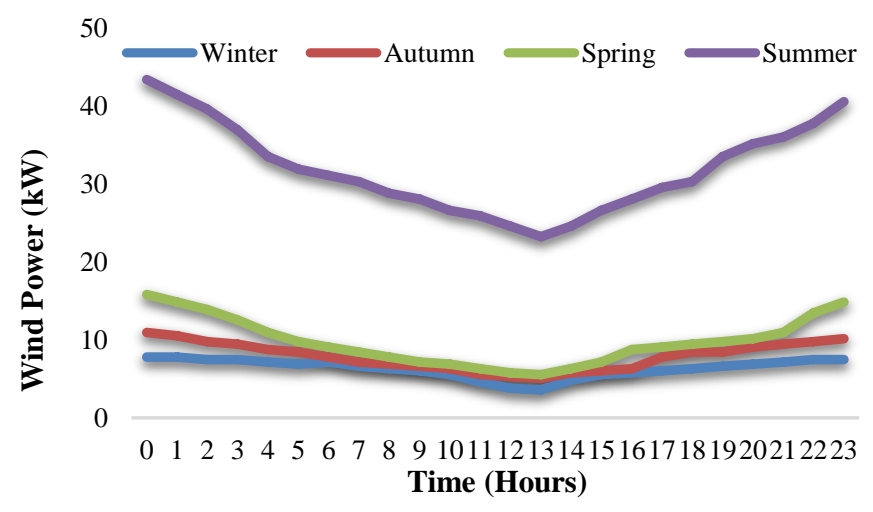

Fig. 11. Solar output power for four seasons response.

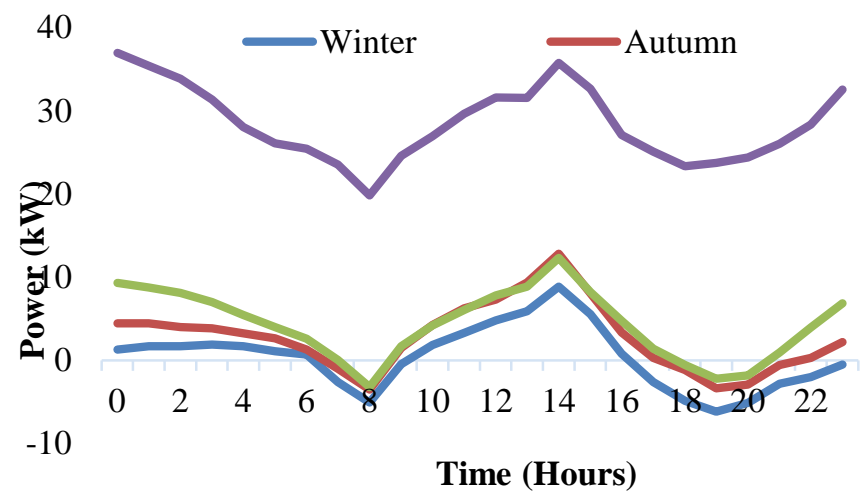

Fig. 12. Excessive power available for storage \& power supplied by the battery during four seasons' response.

\section{CONCLUSION}

This paper proposes a stand-alone hybrid wind/solar/battery energy system. The HES configuration, system unit-sizing, characteristics of the key system components, modeling and overall power management strategy of the suggested standalone hybrid system is discussed. The wind and solar energy sources are utilized as main power producing systems while battery is used as energy storing system. The battery stores surplus power during excessive power generation from wind and solar sources while it supplies power when there is shortage of power generation to meet load requirement. Analytical studies are carried out to verify performance of a proposed system. The analytical studies of the four seasons i.e., winter, spring, summer and autumn, shows the usefulness and feasibility of a suggested stand-alone hybrid wind/solar/battery energy system. Through the experimental investigation, it is clearly observed that the Hybrid system can full the demand of the consumer where yet no power.

\section{REFERENCES}

[1] Wang, Caisheng, and M. Hashem Nehrir. "Power management of a standalone wind/photovoltaic/fuel cell energy system." IEEE transactions on energy conversion 23.3 (2008): pp.957-967.

[2] Krishnan, M. Sivaram, M. Siva Ramkumar, and M. Sownthara. "Power management of hybrid renewable energy system by frequency deviation control." Int. J. Innov. Res. Sci. Eng. Technol 3.3 (2014): pp.763-769.

[3] Ramkumar, M. Sivaram Krishnan M. Siva, and A. Amudha. "Frequency Deviation Control in Hybrid Renewable Energy System Using FCUC." International Journal of Control Theory and Applications 10.2 (2017): pp.333-344.

[4] Nehrir, M. H., et al. "A review of hybrid renewable/alternative energy systems for electric power generation: Configurations, control, and applications." IEEE transactions on sustainable energy 2.4 (2011): pp.392-403.

[5] Baloch, Mazhar Hussain, et al. "A Research on Electricity Generation from Wind Corridors of Pakistan (Two Provinces): A Technical Proposal for Remote Zones", Sustainability. 2017; 9(9):1611.

[6] Baloch, Mazhar Hussain, et al. "Feasible Wind Power Potential from Costal Line of Sindh Pakistan." Research Journal of Applied Sciences, Engineering and Technology 10.4 (2015): 393-400.

[7] Siddique, Muhammad Noman, et al. "Optimal integration of hybrid (wind--solar) system with diesel power plantlnewline using HOMER." Turkish Journal of Electrical Engineering \& Computer Sciences 23.6 (2015): pp.1547-1557.

[8] Rehman, Saif Ur, et al. "Feasibility study of hybrid energy system for offgrid rural electrification in southern Pakistan." Energy Exploration \& Exploitation 34.3 (2016): pp.468-482.

[9] Kant, Jyoti, and Hari Kr Singh. "Scope and Potential of a Hybrid Solar \& Wind Energy System for Jodhpur Region Case study." International Journal of Science and Research (IJSR) 3.6 (2014): pp.1603-1606.

[10] Negi, Swati, and Lini Mathew. "Hybrid renewable energy system: A review." International Journal of Electronic and Electrical Engineering 7.5 (2014): pp.535-42.

[11] Baloch, Mazhar Hussain, et al. "Active and Reactive Power Control of a Variable Speed Wind Energy Conversion System based on Cage Generator." International Journal of Advanced Computer Science and Applications8.9 (2017): pp.197-202.

[12] Baloch, Mazhar H., Ghulam S. Kaloi, and Zubair A. Memon. "Current scenario of the wind energy in Pakistan challenges and future perspectives: A case study." Energy Reports 2 (2016): pp.201-210.

[13] Baloch, Mazhar Hussain, et al. "A Review of the State of the Art Control Techniques for Wind Energy Conversion System." International Journal of Renewable Energy Research (IJRER) 6.4 (2016): 1276-1295.

[14] Chedid, R., H. Akiki, and Saifur Rahman. "A decision support technique for the design of hybrid solar-wind power systems." IEEE transactions on Energy conversion 13.1 (1998): pp.76-83. 
[15] Marisarla, Chaitanya, and K. Ravi Kumar. "A hybrid wind and solar energy system with battery energy storage for an isolated system." International Journal of Engineering and Innovative Technology (IJEIT) Volume 3 (2013): pp.99-104.

[16] Ingole, Ashish S., and Bhushan S. Rakhonde. "Hybrid power generation system using wind energy and solar energy." International Journal of Scientific and Research Publications 5.3 (2015): pp.1-4.

[17] Report: Pakistan Metrological Department (PMD) www.pmd.gov.pk.

[18] Ghulam .S. Kaloi et.al., "Wind Energy Potential at Badin and Pasni Costal Line of Pakistan." International Journal of Renewable Energy Development 6.2 (2017): 103.
[19] Baloch, Mazhar Hussain, et al. "Stability and nonlinear controller analysis of wind energy conversion system with random wind speed." International Journal of Electrical Power \& Energy Systems 79 (2016): 75-83.

[20] Ghulam .S. Kaloi et.al., "Dynamic Modeling and Control of DFIG for Wind Energy Conversion System Using Feedback Linearization, Journal of Electrical Engg. and Technology (JEET), 11.5(2016): pp-1137-1146.

[21] Ghulam .S. Kaloi et.al., "Active and reactive power control of the doubly fed induction generator based on wind energy conversion system." Energy Reports 2 (2016): 194-200 